\title{
Prescribing wellness: comprehensive pain management outside specialist services
}

\section{Simon Holliday \\ Staff specialist \\ General practitioner ${ }^{2}$}

\section{Chris Hayes}

Specialist pain medicine physician $^{3}$

\section{Lester Jones}

Pain educator and PhD candidate $^{4}$

\section{Jill Gordon}

Associate professor in medical education (retired) ${ }^{5}$ General practitioner ${ }^{6}$

\section{Newman Harris}

Consultant psychiatrist and Specialist pain medicine physician ${ }^{7}$

Clinical senior lecturer ${ }^{8}$

\section{Michael Nicholas}

Clinical psychologist ${ }^{7}$

Professor and Director, Pain

Education Unit ${ }^{8}$

1 Drug and Alcohol Clinical

Services, Hunter New

England Local Health

District, Newcastle, NSW

${ }^{2}$ Albert St Medical Centre

Taree, NSW

${ }^{3}$ Hunter Integrated Pain

Service, John Hunter

Hospital, Newcastle, NSW

${ }^{4}$ Discipline of Physiotherapy, Judith Lumley Centre, La

Trobe University, Melbourne

${ }^{5}$ University of Sydney

${ }^{6}$ Lindfield, NSW

${ }^{7}$ Royal North Shore

Hospital, Sydney

8 Pain Management Research Institute, Northern Clinical

School, University of Sydney

\section{Keywords}

analgesia, chronic pain,

opioids, pain management

Aust Prescr 2018;41:86-91

https://doi.org/10.18773/

austprescr.2018.023

First published 15 May 2018

\section{SUMMARY}

Opioids have important roles in the time-limited treatment of acute and cancer pain, end-of-life pain or dyspnoea, and in opioid dependency.

Maintaining focus on biomedical treatments, including drugs, has limited success in chronic pain.

Active self-management and healthy lifestyle choices are fundamental to addressing multisystem complexity and harnessing neuroplasticity in chronic pain.

Addressing psychosocial maladaptations and physical deconditioning requires a variety of approaches, frequently involving multiple care providers.

In practice, most pain care is delivered outside specialist centres by GPs and other non-pain specialists. Although they are well placed to provide multimodal care, they often lack training and confidence in delivering this care.

\section{Introduction}

Codeine rescheduling in February 2018 prevented consumers accessing over-the-counter opioids without a prescription. ' This presents a major challenge because of the number of patients involved - over 15 million packs of over-the-counter opioid analgesics were purchased in Australia in 2013, accounting for $36.6 \%$ of total opioid pack sales. ${ }^{2}$

Chronic pain is defined as pain lasting beyond the time of tissue healing or for over three months. ${ }^{3}$ Almost half of GP consultations involve some discussion of pain, usually relegated behind comorbidities such as obesity and diabetes or psychiatric and substance-use disorders. ${ }^{4,5}$ Chronic pain challenges classic models of diagnosis and treatment.

Trials indicate that the best care for chronic pain involves self-management by the patient and a multidisciplinary approach through a pain centre rather than GP 'treatment as usual'.6-9 However, a large US outpatient study found that only $0.12 \%$ of chronic pain consultations involved pain specialists. ${ }^{10}$ While less expensive, GP care does not become cost effective until it addresses physical disability alongside pain-related thoughts, emotions and behaviours." However, GPs have the advantage of capacity, accessibility (geographical and financial) and the potential to provide longitudinal, holistic and opportunistic care.7 For this reason, it is important
GPs do not feel that treating chronic pain simply requires a choice between prescribing opioids or referring to specialist care.

Multimodal, multidisciplinary chronic pain care can be translated into time-poor primary care settings. Practice policies, holistic assessment then drug and non-drug approaches need to be explored.

\section{Practice policies}

A proactive pain management approach that begins at the reception desk can encourage optimum care. Suitable practice policies include refusing phone scripts, ensuring continuity of care with one doctor, displaying a sign about the opioid policy, and using Medicare items that support complex and collaborative care.

\section{Ongoing holistic assessment}

Even in acute pain, standard care is enhanced by a broad, 'whole person' assessment. The psychosocial dimension includes assessment of mood, cognitions, trauma, suicide risk and the social context of the presenting problems (e.g. workers' compensation, family issues). Additional components incorporate physical activity, sleep patterns, nutrition, and past or current use of addictive substances including prescription drugs. Practice nurses can play a role in implementing time-efficient assessments of chronic pain. 
Practical steps for assessment include:

- Regular use of validated brief outcome tools. Just asking patients how bad their pain is out of 10 is simplistic in chronic pain and tends to elicit default opioid prescriptions. ${ }^{12}$ The three-item PEG scale allows a broader and readily repeatable assessment and only requires a few extra seconds. ${ }^{13}$

- Assessing cognitive aspects. Identify psychosocial risks early using a tool such as the ten-item Örebro Musculoskeletal Pain Screening Questionnaire. ${ }^{14}$ Ask what the patient is concerned about or fears the most regarding their pain. This will guide targeted reassurance..$^{15}$

- Assessing physical activity. Use the Five Times Sit to Stand Test (taking over 15 seconds correlates with an increased risk of falls). ${ }^{16}$ The patient should be encouraged to do the best they can without significantly flaring their pain.

\section{Why opioids are no longer first line}

Guidelines for using opioids to treat pain have changed markedly, with prescription now being recommended only for acute pain, active cancer pain or palliative care. There is evidence to support longterm opioids as substitution therapy to minimise harm from dependency in opioid use disorders.

Prescribing opioids for over a week for acute pain doubles the risk of long-term use at one year ( $6 \%$ to $13 \%$ ) and this risk doubles again (to $29.9 \%$ ) if the initial prescription lasts a month. ${ }^{17}$ Dispensing in Australia increased 15-fold between 1992 and 2012, predominantly reflecting long-term opioid provision for chronic pain. ${ }^{18}$

The absence of long-term efficacy data has finally been addressed in a landmark randomised controlled trial of long-term opioids compared to non-opioid medicines for chronic musculoskeletal pain. During a year of collaborative care, the initiation of opioids failed to improve function, but caused more adverse effects and marginally worse pain intensity. ${ }^{19}$

Adverse effects include opioid-induced hyperalgesia and tolerance which cause a perceived increase in pain and need for dose escalation. Recent animal and human studies indicate that opioids may actually contribute directly to chronic pain. This toxicity may commence after brief exposure and leave a vulnerability to increased pain responses that may be of indefinite duration. ${ }^{20}$ Other long-term opioid toxicities include depression, sleep interference, hypogonadism, prolonged disability and delayed return to work. ${ }^{21-23}$
Suggested strategies to mitigate the risk of addiction (i.e. universal precautions) resemble an assortment of opioid substitution therapy approaches. However, these strategies fail to reliably predict or identify abusers or mitigate risks, ${ }^{3,6}$ and are rarely implemented by GPs. ${ }^{24}$ When initiated with dose reduction, risk mitigation strategies do not worsen pain control or quality of life. ${ }^{25}$

\section{Tapering or stopping opioids}

In general, introducing multimodal chronic pain care will facilitate opioid tapering or cessation and so improve pain outcomes and lower opioid-related risks both to patients and, when diverted, to their social network. ${ }^{26}$ GPs need to first estimate total opioid dose in morphine equivalents using conversion tables. ${ }^{27}$ Starting at a lower equivalent dose when rotating or simplifying regimens will reduce the risk of overdose. The deprescribing process may prove challenging gradual weaning may be derailed by an abstinence syndrome involving insomnia, emotional blunting, deficits in executive control and the exacerbation or re-emergence of comorbid psychiatric disorders. ${ }^{28}$ If an attempt at deprescribing has been unsuccessful, it may be wise to plan a slower taper or consider opioid substitution therapy.

It is unwise to assume that new patients already taking opioids have a continuing need for opioid prescription. Difficult conversations may follow as doctors explain why opioids are no longer recommended for chronic pain. The requirement to comply with relevant state or territory regulations is protective in this setting. ${ }^{29}$ In some cases, providing limited dispensing and 'methadone-style' supervision may help to minimise harms such as abuse or overdose. It is important to consider safety strategies such as take-home naloxone for patients and families, ${ }^{30}$ fentanyl patch exchanges ${ }^{6}$ and the avoidance of benzodiazepine co-prescription. ${ }^{3,6}$

\section{Non-opioid medicines}

Patients consider meaningful chronic pain relief equates to at least $50 \%$ reduction in pain intensity. A systematic review found medicines, opioids or otherwise, do not achieve this for most patients. ${ }^{31}$ This finding was endorsed recently by a Canadian review of the limited evidence for non-opioid analgesics which included non-steroidal anti-inflammatory drugs, antidepressants and antiepileptics such as pregabalin and gabapentin. ${ }^{6}$

As well as practising evidence-based medicine, doctors should identify and stop harmful or ineffective therapies. Regular pain reviews facilitate the early deprescribing of ineffective medicines. ${ }^{31}$ 


\section{More effective approaches}

Recent concepts of pain look past any nociceptive (damaged tissue) or neuropathic (damaged nerve) contributors, to the role of brain interpretation, central sensitisation, descending modulation and immune and endocrine activation. ${ }^{32-34}$ The interpretation of pain by the brain involves encoding of signals from multiple sources and is more likely to occur when the person perceives a threat or danger. The pain experience is dampened or amplified by the dopamine (reward) system and the limbic system (emotions, motivations, learning and memory). Current theorists conceptualise pain as a warning system that consciously or unconsciously selects which behaviours will ensure the survival of the individual or their tribe. ${ }^{35}$

We need to educate patients that, just as their chronic pain is not a simple readout of the severity of tissue damage, their pain management must move beyond a narrow sensory focus. Education allows patients to reframe their treatment needs away from solely tissue-focused and passively received interventions. Explaining the neuroscience of pain has actually been shown to improve pain, movement and fear-avoidance, ${ }^{36}$ especially when provided with active strategies such as encouraging the patient to gradually resume normal activities in a paced manner and assistance with sleep disturbance.

Ultimately, non-drug interventions have the potential to improve outcomes for chronic pain and comorbidities $^{4}$ and tend to be low-tech, low-cost and low-risk. GPs can deliver multimodal care themselves in micro-interventions over multiple consultations. ${ }^{7,37}$ They can supplement their patient care with workbook and online programs (see Box) or may collaborate with or refer to allied health providers.

\section{Physical treatment}

Establishing safe, consistent patterns of movement can calm nervous system arousal and reduce central sensitisation. ${ }^{38,39}$ This can be facilitated by negotiating treatment goals that reflect meaningful and enjoyable activities, not just pain relief. Goals should be achievable and measurable with activities starting well below what the patient can do before gradually building their functional capacity. For example, sit-tostand exercises can be used as the basis of a simple home-based strength program, starting from a raised seat height to reduce effort. Activity pacing and graded exercise avoids the 'boom then bust' trap and helps reduce pain, fatigue and depression. ${ }^{4}$

Pacing encourages patients to maintain relatively constant daily activity despite their pain levels. This means capping activity at the daily goal when pain is mild and using self-management strategies to increase activity to the daily goal when pain is more severe. Rotating time-limited activities decreases the frequency and often the intensity of pain flare-ups and potential recourse to opioids. ${ }^{40}$ Behavioural activation, delivered by clinicians without specialist training, may also improve depression as effectively as formal cognitive behavioural therapy. ${ }^{41}$

\section{Psychological treatments}

It is important to explore any cognitive, behavioural and affective factors contributing to pain and suffering. Clinicians can help patients to recognise and modify unhelpful cognitions such as catastrophising, 'black and white' thinking and beliefs that drive fear-avoidance behaviours. ${ }^{15,42,43}$ It is critical to identify and treat depression or anxiety. ${ }^{42}$ Treatments include encouraging the scheduling of pleasurable activities, relaxation and exercise based on pacing principles. Antidepressants that may have an impact on pain include duloxetine and low-dose amitriptyline. Relaxation strategies, mindfulness, self-awareness and non-judgemental acceptance can help to self-regulate distress in the presence of pain. ${ }^{42}$ As well as directly supporting pain self-management, calming the nervous system and mind assists in alleviating insomnia and anxiety.

Patients frequently report using tobacco, cannabis and alcohol as a coping strategy. ${ }^{22}$ Despite the perception of short-term relief, these substances retard function by disturbing learning, memory and sleep architecture. ${ }^{22}$ For insomnia, first-line management involves cognitive behavioural strategies including sleep or bedtime restriction, avoiding screens before bedtime and other sleep hygiene measures. ${ }^{44}$

\section{Social engagement}

People typically feel safe when socially well connected and feel under threat when isolated. Meaningful positive social engagement at work or home is crucial for pain recovery. For example, the pain threshold is elevated when sharing a laugh with friends. ${ }^{45}$ Partners may aid recovery by being goal-oriented and by avoiding being unreasonably critical or over-solicitous. When sexual intimacy has been lost, re-establishing it may require an adaptation of activity pacing known as sensate focusing. ${ }^{46}$

\section{Nutrition}

As with other chronic metabolic illnesses, obesity is frequently associated with chronic pain. ${ }^{47}$ The gut microbial profile or microbiome has been hypothesised to be the nexus between the Western diet and the maladaptations in the nervous, immune and endocrine systems. ${ }^{48}$ These may interlink with a lowgrade inflammatory state (metaflammation). ${ }^{34}$ Simple nutritional interventions for pain encourage consuming five serves of vegetables per day and two of fruit while reducing intake of sugary and processed foods. ${ }^{34}$ 


\section{Conclusion}

Long-term opioid therapy for analgesia is a surrogate for simplistic conceptualisations of pain and leads to inadequate pain management. ${ }^{7}$ Effective care includes moving beyond a focus on pain relief and prescribing drugs. To do this, clinicians need to be familiar with the alternatives and become confident in their use so they can help patients to understand the benefits of deprescribing. However, some patients will require opioid substitution therapy.

A medical system that rewards rapid patient throughput, subsidises opioid analgesics, and focuses on 'quick fixes' will never untangle the many strands of suffering contributing to chronic pain. We need to give our patients hope for wellness and some sense of control over their adversity. Opioid deprescribing together with multimodal measures will improve individual and public health, and reduce chronic pain and associated comorbidities. ${ }^{4,26}<$

Chris Hayes has undertaken sponsored consultancy and educational work with Mundipharma, Janssen and Pfizer prior to 2013. Newman Harris declares payments for services from Mundipharma, Janssen and Pfizer. Michael Nicholas receives royalties from a book listed in the Box (Manage your Pain).

Acknowledgement: The authors would like to acknowledge the contributions of Cathy Fraser and Parker Magin

\section{Box Pain management resources}

\section{Clinician resources}

Australian Pain Management Association. Pacing activity. Brisbane: APMA; 2015. www.painmanagement.org.au/2014-09-11-13-35-53/ 2014-09-11-13-36-47/166-pacing.html [cited 2018 Mar 27]

Sleep restriction therapy. San Jose, CA: Kaiser Permanente; 2006. https://thrive.kaiserpermanente.org/care-near-you/northern-california/ sanjose/wp-content/uploads/sites/7/2015/10/sleep-restriction-rev2 tcm28-557887.pdf [PDF] [cited 2018 Mar 27]

Pain intensity, Enjoyment of life, General activity (PEG) assessment tool. https://ndarc.med.unsw.edu.au/sites/default/files/ndarc/page/PEG.pdf [PDF] [cited 2018 Mar 27]

[Example of a sign for the waiting room explaining the practice's opioid and benzodiazepine medication policy to patients] https://ndarc.med.unsw.edu.au/sites/default/files/ndarc/page/GP\%20 Prescribing\%20Practice\%20Sign.pdf [PDF] [cited 2018 Mar 27]

\section{Training}

Faculty of Pain Medicine, Australian and New Zealand College of Anaesthetists. Better pain management: pain education for professionals. [Twelve brief online education modules] https://www.betterpainmanagement.com [cited 2018 Mar 27]

Pain Management Research Institute, University of Sydney. Webinar skills training in pain management: putting cognitive behavioural therapy skills into practice. [Online, interactive webinars training in CGT skills for pain] http://sydney.edu.au/medicine/pmri/education/ continuing/webinar.php [cited 2018 Mar 27]

Non-pharmacological management of chronic pain. Presented by the Black Dog Institute [recorded webinar]. https://medcast.com.au/ courses/109 [cited 2018 Mar 27]

\section{Books}

Davies S, Cooke N, Sutton J. Rewire your pain: an evidence based approach to reduce chronic pain. Brisbane: Australian Pain Management Association; 2015

Nicholas M, Molloy A, Tonkin L, Beeston L. Manage your pain: practical and positive ways of adapting to chronic pain. 3rd ed. Sydney: Harper Collins Publishers Australia; 2011.

Edelman S. Change your thinking with CBT: overcome stress, combat anxiety and improve your life. London: Ebury Publishing: 2006.

\section{Websites}

Pain Management Network. Sydney: Agency for Clinical Innovation; 2018. www.aci.health.nsw.gov.au/chronic-pain [cited 2018 Mar 27]

painHEALTH. Easing musculoskeletal pain. Perth: painHEALTH; 2017. https://painhealth.csse.uwa.edu.au [cited 2018 Mar 27]

Hunter New England Local Health District. Pain. Newcastle: Hunter Integrated Pain Service; 2016. www.hnehealth.nsw.gov.au/Pain/Pages/ Pain.aspx [cited 2018 Mar 27]

\section{Patient online training in cognitive behaviour therapy for pain} https://thiswayup.org.au. This program seeks to reproduce training provided at a multidisciplinary clinic. It costs $\$ 59$ for eight lessons and participants may access it over a year. Participants need to be referred by a registered clinician who can then receive feedback about their patients' progress.

https://mindspot.org.au/pain-course. This program is free and is accessible without a referral. It provides five mental health self-help lessons over two months with weekly support from a therapist. A YouTube introduction is available.

www.cci.health.wa.gov.au/resources/consumers.cfm. Centre for Clinical Interventions. Consumer resources. Perth: Government of Western Australia Department of Health; 2016.

\section{Brainman brief educational videos}

Understanding pain in less than 5 minutes, and what to do about it! 2013 Jan 15. www.youtube.com/watch?v=C 3phB93rvl [cited 2018 Mar 27]

Understanding Pain: Brainman stops his opioids. 2014 Oct 3. www.youtube.com/watch?v=Ml1myFQPdCE [cited 2017 Mar 27]

Understanding Pain: Brainman chooses. 2014 Oct 3. www.youtube.com/watch?v=jlwn9rC3rOl [cited 2017 Mar 27] 


\section{REFERENCES}

1. Roberts DM, Nielsen S. Changes for codeine [editorial]. Aust Prescr 2018;41:2-3. https://doi.org/10.18773/ austprescr.2018.006

2. Degenhardt L, Gisev N, Cama E, Nielsen S, Larance B, Bruno R. The extent and correlates of communitybased pharmaceutical opioid utilisation in Australia Pharmacoepidemiol Drug Saf 2016;25:521-38. https://doi.org/10.1002/pds.3931

3. Dowell D, Haegerich TM, Chou R. CDC guideline for prescribing opioids for chronic pain - United States, 2016 MMWR Recomm Rep 2016;65(no. RR-1):1-49. https://doi.org/ 10.15585/mmwr.rr6501el

4. Barbour KE, Helmick CG, Boring M, Brady TJ. Vital signs: prevalence of doctor-diagnosed arthritis and arthritisattributable activity limitation - United States, 2013-2015. MMWR Morb Mortal Wkly Rep 2017;66:246-53. https://doi.org/10.15585/mmwr.mm6609e

5. Tai-Seale M, Bolin J, Bao X, Street R. Management of chronic pain among older patients: inside primary care in the US. Eur J Pain 2011;15:1087.e1-8. https://doi.org/10.1016/ j.ejpain.2011.06.012

6. Busse JW Craigie S, Juurlink DN, Buckley DN, Wang L, Couban RJ, et al. Guideline for opioid therapy and chronic noncancer pain. CMAJ 2017;189:E659-66. https://doi.org/ 10.1503/cmaj.170363

7. Finestone HM, Juurlink DN, Power B, Gomes T, Pimlott N. Opioid prescribing is a surrogate for inadequate pain management resources. Can Fam Physician 2016;62:465-8.

8. Nicholas MK, Blyth FM. Are self-management strategies effective in chronic pain treatment? Pain Manag 2016;6:75-88. https://doi.org/10.2217/pmt.15.57

9. Kamper SJ, Apeldoorn AT, Chiarotto A, Smeets RJ, Ostelo RW, Guzman J, et al. Multidisciplinary biopsychosocia rehabilitation for chronic low back pain: Cochrane systematic review and meta-analysis. BMJ 2015;350:h444. https://doi.org/10.1136/bmj.h444

10. Rasu RS, Knell ME. Determinants of opioid prescribing for nonmalignant chronic pain in US outpatient settings. Pain Med 2018;19:524-32. https://doi.org/10.1093/pm/pnx025

11. Lin CW, Haas M, Maher CG, Machado LA, van Tulder MW. Cost-effectiveness of general practice care for low back pain: a systematic review. Eur Spine J 2011;20:1012-23. https://doi.org/10.1007/s00586-010-1675-4

12. Ballantyne JC, Sullivan MD. Intensity of chronic pain the wrong metric? N Engl J Med 2015;373:2098-9. https://doi.org/10.1056/NEJMp1507136

13. Krebs EE, Lorenz KA, Bair MJ, Damush TM, Wu J, Sutherland JM, et al. Development and initial validation of the PEG, a three-item scale assessing pain intensity and interference. J Gen Intern Med 2009;24:733-8. https://doi.org/10.1007/s11606-009-0981-1

14. Linton SJ, Nicholas M, MacDonald S. Development of a short form of the Örebro Musculoskeletal Pain Screening Questionnaire. Spine 2011;36:1891-5. https://doi.org/10.1097/ BRS.0b013e3181f8f775

15. Traeger AC, Hübscher M, Henschke N, Moseley GL, Lee H, McAuley JH. Effect of primary care-based education on reassurance in patients with acute low back pain: systematic review and meta-analysis. JAMA Intern Med 2015;175:733-43. https://doi.org/10.1001/jamainternmed.2015.0217

16. Simmonds MJ, Olson SL, Jones S, Hussein T, Lee CE, Novy D, et al. Psychometric characteristics and clinical usefulness of physical performance tests in patients with low back pain. Spine 1998;23:2412-21. https://doi.org/10.1097/ 00007632-199811150-00011

17. Shah A, Hayes CJ, Martin BC. Characteristics of initial prescription episodes and likelihood of long-term opioid use - United States, 2006-2015. MMWR Morb Mortal Wkly Rep 2017;66:265-9. https://doi.org/10.15585/mmwr.mm6610a1

18. Blanch B, Pearson SA, Haber PS. An overview of the patterns of prescription opioid use, costs and related harms in Australia. Br J Clin Pharmacol 2014;78:1159-66. https://doi.org/10.1111/bcp.12446

19. Krebs EE, Gravely A, Nugent S, Jensen AC, DeRonne B, Goldsmith ES, et al. Effect of opioid vs nonopioid medications on pain-related function in patients with chronic back pain or hip or knee osteoarthritis pain: the SPACE randomized clinical trial. JAMA 2018:319:872-82. https://doi.org/10.1001/jama.2018.0899
20. Grace PM, Strand KA, Galer EL, Urban DJ, Wang X, Baratta MV, et al. Morphine paradoxically prolongs neuropathic pain in rats by amplifying spinal NLRP3 inflammasome activation. Proc Natl Acad Sci USA 2016;113:E3441-50. https://doi.org/10.1073/pnas.1602070113

21. Scherrer JF, Salas J, Copeland LA, Stock EM, Ahmedani BK, Sullivan MD, et al. Prescription opioid duration, dose, and increased risk of depression in 3 large patient populations. Ann Fam Med 2016;14:54-62. https://doi.org/10.1370/ afm.1885

22. Angarita GA, Emadi N, Hodges S, Morgan PT. Sleep abnormalities associated with alcohol, cannabis, cocaine, and opiate use: a comprehensive review. Addict Sci Clin Pract 2016;11:9. https://doi.org/10.1186/ s13722-016-0056-7

23. Tao XG, Lavin RA, Yuspeh L, Weaver VM, Bernacki EJ. The association of the use of opioid and psychotropic medications with workers' compensation claim costs and lost work time. J Occup Environ Med 2015;57:196-201. https://doi.org/10.1097/JOM.0000000000000333

24. Holliday S, Magin P, Dunbabin J, Oldmeadow C, Henry JM, Lintzeris $\mathrm{N}$, et al. An evaluation of the prescription of opioids for chronic nonmalignant pain by Australian general practitioners. Pain Med 2013;14:62-74. https://doi.org/10.1111/ j.1526-4637.2012.01527.x

25. Thakral M, Walker RL, Saunders K, Shortreed SM, Parchman M, Hansen RN, et al. Comparing pain and depressive symptoms of chronic opioid therapy patients receiving dose reduction and risk mitigation initiatives to usual care. J Pain 2018;19:111-20. https://doi.org/10.1016/ j.jpain.2017.09.006

26. Sullivan MD, Turner JA, DiLodovico C, D’Appollonio A, Stephens K, Chan YF. Prescription opioid taper support for outpatients with chronic pain: a randomized controlled trial. J Pain 2017;18:308-18. https://doi.org/10.1016/ j.jpain.2016.11.003

27. Faculty of Pain Medicine, Australian and New Zealand College of Anaesthetists. Opioid dose equivalence: calculation of oral Morphine Equivalent Daily Dose (oMEDD). Appendix 2 in: Recommendations regarding the use of opioid analgesics in patients with chronic non-cancer pain. PM01. Melbourne: ANZCA; 2015. http://fpm.anzca.edu.au/ resources/professional-documents [cited 2018 Mar 26]

28. Manhapra A, Arias AJ, Ballantyne JC. The conundrum of opioid tapering in long-term opioid therapy for chronic pain: a commentary. Subst Abus 2017;20:1-10. https://doi.org/ 10.1080/08897077.2017.1381663

29. Jammal W, Gown G. Opioid prescribing pitfalls: medicolegal and regulatory issues. Aust Prescr 2015;38:198-203. https://doi.org/10.18773/austprescr.2015.069

30. McDonald R, Campbell ND, Strang J. Twenty years of takehome naloxone for the prevention of overdose deaths from heroin and other opioids: conception and maturation. Drug Alcohol Depend 2017;178:176-87. https://doi.org/10.1016/ j.drugalcdep.2017.05.001

31. Moore A, Derry S, Eccleston C, Kalso E. Expect analgesic failure: pursue analgesic success. BMJ 2013;346:f2690. https://doi.org/10.1136/bmj.f2690

32. Kosek E, Cohen M, Baron R, Gebhart GF, Mico JA, Rice AS, et al. Do we need a third mechanistic descriptor for chronic pain states? Pain 2016;157:1382-6. https://doi.org/10.1097/ j.pain.0000000000000507

33. Jones LE. Stress, pain and recovery: neuro-immuneendocrine interactions and clinical practice. In: Stuart Porter, editor. Psychologically-informed physiotherapy: embedding psychosocial perspectives within clinical management: London: Elsevier; 2017. p. 252.

34. Hayes C, Naylor R, Egger G. Understanding chronic pain in a lifestyle context: the emergence of a whole-person approach. Am J Lifestyle Med 2012;6:421-8. https://doi.org/ $10.1177 / 1559827612439282$

35. Ballantyne JC, Sullivan MD. Discovery of endogenous opioid systems: what it has meant for the clinician's understanding of pain and its treatment. Pain 2017;158:2290-300. https://doi.org/10.1097/j.pain.0000000000001043

36. Louw A, Zimney K, Puentedura EJ, Diener I. The efficacy of pain neuroscience education on musculoskeletal pain: a systematic review of the literature. Physiother Theory Pract 2016;32:332-55. https://doi.org/10.1080/09593985.2016.1194646 
37. Dear BF, Gandy M, Karin E, Ricciardi T, Fogliati VJ, McDonald S, et al. The pain course: a randomised controlled trial comparing a remote-delivered chronic pain management program when provided in online and workbook formats. Pain 2017;158:1289-301. https://doi.org/ 10.1097/j.pain.0000000000000916

38. Sluka KA, O’Donnell JM, Danielson J, Rasmussen LA. Regula physical activity prevents development of chronic pain and activation of central neurons. J Appl Physiol 2013;114:725-33. https://doi.org/10.1152/japplphysiol.01317.2012

39. Ellingson LD, Shields MR, Stegner AJ, Cook DB. Physical activity, sustained sedentary behavior, and pain modulation in women with fibromyalgia. J Pain 2012;13:195-206. https://doi.org/10.1016/j.jpain.2011.11.001

40. Nicholas MK. Can patients' daily behaviour patterns contribute to overuse of opioids? Pain 2016:157:286-7. https://doi.org/10.1097/j.pain.0000000000000408

41. Richards DA, Ekers D, McMillan D, Taylor RS, Byford S, Warren FC, et al. Cost and outcome of behavioural activation versus cognitive behavioural therapy for depression (COBRA): a randomised, controlled, non-inferiority trial. Lancet 2016;388:871-80. https://doi.org/10.1016/ S0140-6736(16)31140-0

42. Purdie F, Morley S. Compassion and chronic pain. Pain 2016:157:2625-7. https://doi.org/10.1097/ j.pain.0000000000000638
43. Main CJ, Buchbinder R, Porcheret M, Foster N. Addressing patient beliefs and expectations in the consultation. Best Pract Res Clin Rheumatol 2010;24:219-25 https://doi.org/10.1016/j.berh.2009.12.013

44. Cunnington D, Junge M. Chronic insomnia: diagnosis and non-pharmacological management. BMJ 2016;355:i5819. https://doi.org/10.1136/bmj.i5819

45. Manninen S, Tuominen L, Dunbar R, Karjalainen T, Hirvonen J, Arponen E, et al. Social laughter triggers endogenous opioid release in humans. J Neurosci 2017;0688-16. https://doi.org/ 10.1523/JNEUROSCI.0688-16.2017

46. Edwards S, Mandeville A, Petersen K, Herron K, Keeling A, Merali Z, et al. 'Re-Connect': a model for working with persistent pain patients on returning to sexual activity (088). In: Abstracts of the Annual Scientific Meeting 2015 Br J Pain 2015;9(2 Suppl):5-75. https://doi.org/10.1177/ 2049463715579924

47. Brain K, Burrows T, Rollo ME, Hayes C, Hodson FJ, Collins CE. Population characteristics in a tertiary pain service cohort experiencing chronic non-cancer pain: weight status, comorbidities, and patient goals. Healthcare (Basel) 2017;5:28. https://doi.org/10.3390/healthcare5020028

48. Fleck AK, Schuppan D, Wiendl H, Klotz L. Gut-CNS-Axis as possibility to modulate inflammatory disease activity implications for multiple sclerosis. Int J Mol Sci 2017;18:1526. https://doi.org/10.3390/ijms18071526 